\title{
The C-Type Lectin Mincle: Clues for a Role in Crohn's Disease Adjuvant Reaction
}

\author{
Anje A. te Velde* \\ Tytgat Institute for Liver and Intestinal Research, Academic Medical Center, Amsterdam, Netherlands
}

Keywords: Mincle review, adjuvants, C-type lectin, Mycobacterium, Crohn's disease

The term adjuvant is predominantly used when discussing vaccines, but only mimics how normally infections activate the immune system to secure that an innate immune reaction induces dendritic cells (DCs) to become optimally stimulatory for $\mathrm{T}$ cells. The interaction with the pathogen determines the different signals that are needed for a DC to become fully operated and give the proper polarizing factors to the differentiating $\mathrm{T}$ cell. Optimal co-stimulation requires a signal that is provided by upregulated receptors (CD80 and CD86) on DCs, and the T cell polarizing signal is mediated by various soluble or membrane-bound factors, like IL-12 for Th1 cell polarization. These signals are provided by ligation of pattern recognition receptors (PRRs), such as toll-like receptors (TLRs) and C-type lectins that can sense infection through recognition of pathogen-associated molecular patterns (PAMPs) or various inflammatory tissue factors (1).

Resting macrophages have low major histocompatibility complex class II and co-stimulatory molecules expressed on their surface. Macrophages can take up microorganisms via receptors such as scavenger receptors, complement receptors, and C-type lectins for degradation in phagosomes resulting in peptides for presentation. Macrophages also continuously scavenge dead or dying cells. These are a rich source of self-antigens, so it is very important that they do not activate naïve $\mathrm{T}$ cells when there is no ongoing microbial infection.

In Crohn's disease (CD), a chronic inflammatory bowel disease (IBD), multiple factors have been described that contribute to disease pathogenesis (2). The exact etiology of IBDs still remains unknown, although it is thought that the diseases result from an excessive immune response directed against microbial or environmentally derived antigens that can be triggered by the disruption of the intestinal epithelial barrier integrity. The resulting inflammation is a very general reaction; a specific antigen mediating the inflammation has never been identified. The response is induced by the luminal microbiota, where microbial antigens as adjuvants stimulate the immune reaction. This results in activated innate (macrophages and neutrophils) and adaptive (Th1/Th17 and B lymphocytes) responses (3). In this respect, $\mathrm{CD}$ includes many characteristics of an immunologic adjuvant reaction.

Most proteins are poor immunogens when injected alone. Various substances that induce co-stimulatory, adjuvant, activity have been added in vaccines for a long time to induce appropriate antibody responses. Vaccines containing bacterial products, necessary for $\mathrm{T}$ cell responses, are very potent and therefore use in humans is limited. In recent years, the development of adjuvants that induce a strong cellular response has shifted from an empirical to a rational process based on knowledge of molecular mechanisms. A major breakthrough was the identification of the C-type lectin Mincle (macrophage-inducible C-type lectin) as one of the main receptors involved (4-6).

In this opinion article, I provide clues that the cellular adjuvant reaction that characterizes the pathophysiology of $\mathrm{CD}$ might be mediated by signaling via Mincle. 


\section{MINCLE}

Mincle (also called clec4e or clecsf9) was first described as a downstream target of NF-IL6 (also named C/EBP- $\beta$ ), a transcription factor, in macrophages (7). They demonstrate that Mincle mRNA was strongly induced in response to several inflammatory stimuli, such as LPS, TNF- $\alpha$, IL- 6 , and IFN- $\gamma$ in murine macrophages. A few years later, Mincle was grouped together with macrophage C-type lectin (MCL), DC immunoreceptor, and Dectin-2 (DC-associated lectin-2) as type II-related C-type lectins (8). These genes were mapped in an arthritis susceptibility locus in a rat model and the first indication for an immune activating function of Mincle was proposed (9). Mincle serves as a receptor for various bacteria, fungi, and other molecules (listed in Figure 1A). Mincle signals via association with the $\mathrm{FcR} \gamma$ chain that contains an activating receptor coupled with an immunoreceptor tyrosine-based activation motif, ultimately resulting in activation of NF- $\mathrm{KB}(10)$.

The first suggestion that Mincle is a receptor for a cell wall component of Mycobacterium tuberculosis, the glycolipid trehalose-6,6'-dimycolate (TDM, also named cord factor), was made when it appeared to be involved in a characteristic process of mycobacterial infection: the formation of granulomas (4). Mycobacteria can persist in normal tissues (39); recruitment of Mincle by TDM coupled to immunoglobulin G-opsonized beads interferes with phagosome maturation (40). The activity of Mincle is mediated by a ligand binding site that is conserved in a wide range of mammalian species (41). The Th1/Th17 adjuvanticity of TDM and its synthetic analog trehalose-6,6'-dibehenate (TDB) including its molecular mechanism via Syk and Card9 was confirmed in several studies $(5,6,42)$.

Mincle protein is barely detectable on resting cells $(4,42)$. In experiments in various tissues in rhesus macaques, the frequencies of $\mathrm{CD} 14^{+}$gated cells that express Mincle in colon and ileum were low compared with bone marrow, liver, spleen, and lymph nodes (43). Induction of Mincle expression was shown to be induced by several pathogenic and non-pathogenic stimuli. Mincle was shown to be induced by TDM in the absence of Mincle protein expression via MCL (also called dectin-3) that was constitutively expressed in myeloid cells (44-46) through protein-protein interaction via its stalk region (47). C/EBP- $\beta$ is the central hub in Mincle expression and connects TLR4 signals to TDB/TDM responsiveness through MyD88-dependent upregulation of Mincle $(32,48)$.

\section{MINCLE AND CD}

In literature, there is no direct link that connects Mincle to CD. There is, however, already a lot of information that links Mincle to other diseases. Most of these are also inflammatory-mediated diseases, such as rheumatoid arthritis $(49,50)$, allergic skin inflammation (28) and post-ischemic inflammation $(51,52)$, and other experimental inflammatory models (53-58).

Mincle has been shown to regulate numerous cellular responses including phagocytosis, endocytosis, respiratory burst, Nlrp3 inflammasome activation, NET formation, pro-inflammatory cytokine, and chemokine production and promotes Th1/Th17 responses [recently reviewed in Ref. $(59,60)]$. These are all inflammatory reactions that have been described to play a role in $\mathrm{CD}$. In Figure 1A, the different factors that are involved in Mincle signaling and also associated with $\mathrm{CD}$ are highlighted and discussed beneath.

As indicated, Mincle can act as a receptor for several different pathogens. The question is if these microorganisms have also been associated with CD. For Mycobacterium avium subspecies paratuberculosis, this is well known, it can be isolated from intestinal tissues and blood samples from CD patients at higher frequency than healthy persons (61). Treatment with antimycobacterial regimens in clinical trials achieved reversal of CD symptoms $(62,63)$. Also other bacteria linked to Mincle have been associated with CD: Listeria monocytogenes, Klebsiella pneumonia, Streptococcus pneumonia, Pneumocystis pneumonia, and Escherichia coli (64-70). A dysfunction in both a specialized form of autophagy, xenophagy, and HIF- $1 \alpha$ was demonstrated to be involved in adherent invasive E. coli infections in CD (71). HIF-1 $\alpha$-induced inducible nitric oxide synthase produces nitric oxide $(\mathrm{NO})$ that was shown to be upregulated in the inflamed mucosa in response to pro-inflammatory cytokines $(72,73)$.

In around $50 \%$ of $\mathrm{CD}$ patients' granulomas can be detected (74). Granulomas are linked to mycobacterium, and Mincle has been shown to be important (75). Several cytokines, including IL-1 and TNF- $\alpha$, have been shown to promote the formation of granulomas (76). These cytokines can be secreted upon stimulation via Mincle after stimulation with TDM-mediated granuloma formation (4).

Toward fungal glycans, it has been demonstrated that human peripheral blood mononuclear cells (PBMCs) from CD patients show a hyperresponsiveness with a central role for Syk and Src signaling (77). PBMCs from patients with CD produce more IFN- $\gamma$ and IL-17 upon exposure to Candida (78).

A well-known complication of $\mathrm{CD}$ is intestinal fibrosis. Recently, it was demonstrated that this was mediated via a PKC 8 mediated redox-dependent signaling process by accumulated advanced oxidation protein products (79).

CARD 9 has been an autoimmune disease-associated gene, and differential expression of this gene might be a functional mechanism underlying observed GWAS signals (80). It coordinates Th17- and IL-22-producing cells in intestinal immune responses after epithelial injury in mice (81). Aberrant regulation of CARD9, either through genetic mutation (e.g., polymorphism) or activation by environmental triggers via Mincle, could contribute to pathological immune activation.

Crohn's disease patients treated with TNF blockers demonstrated an increased risk of opportunistic infections such as mycosis, aspergillosis, pneumocystosis, or cryptococcosis (82) and also Pityrosporum (Malassezia) folliculitis (83), and cutaneous lesions of Leishmaniasis (84).

About $50 \%$ of the world's population carry the Helicobacter pylori bacterium. In a meta-analysis, a negative association was found between $H$. pylori infection and CD. They conclude that H. pylori could exert an immunomodulatory effect in IBD (85) maybe by Mincle-mediated anti-inflammatory signaling (18).

Finally, danger/damage-associated molecular pattern (DAMP)-derived triggers from dead cells may contribute via 
A

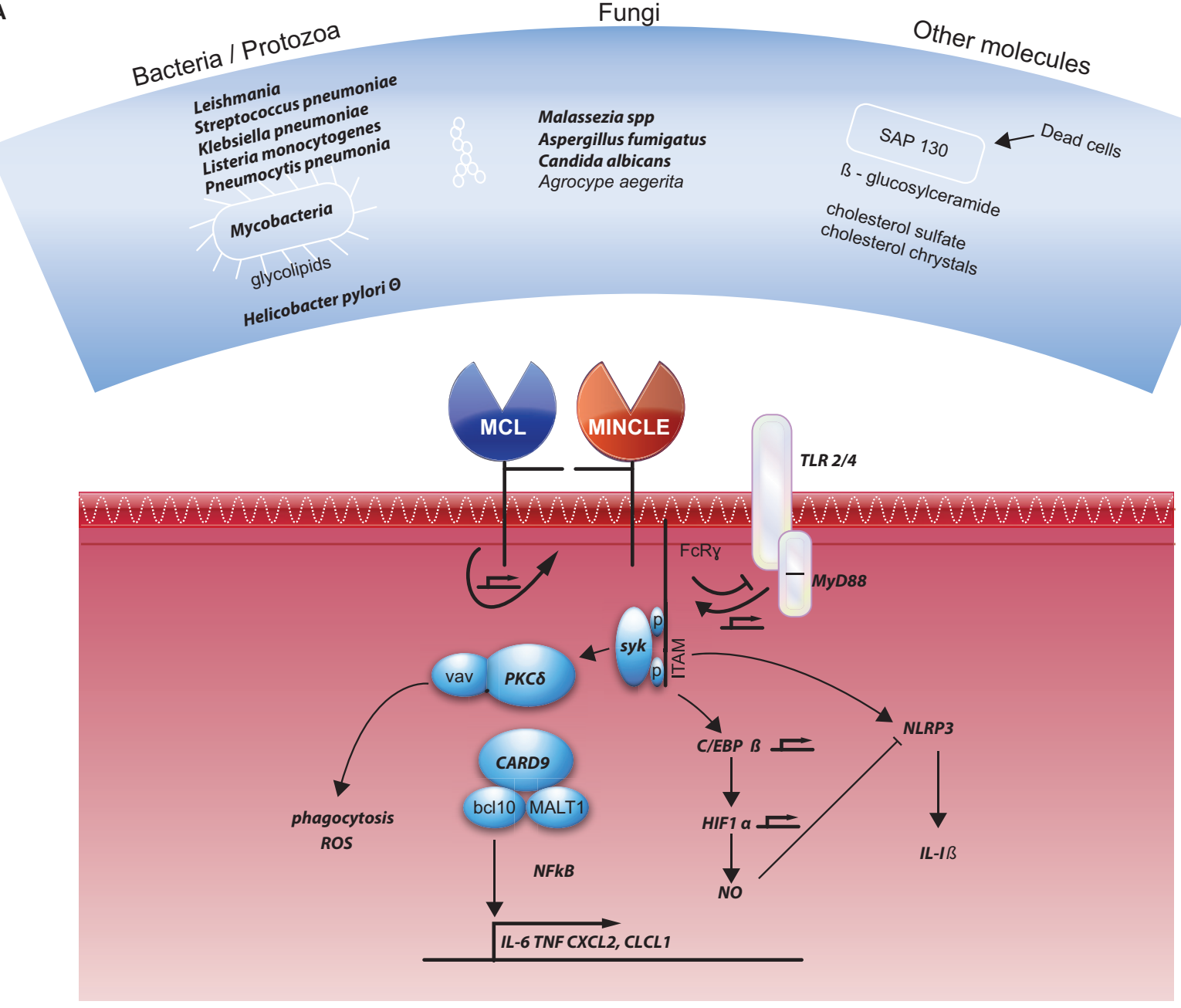

Fungi

Malassezia spp

Aspergillus fumigatus

Candida albicans

cholesterol sulfate
cholesterol chry

B
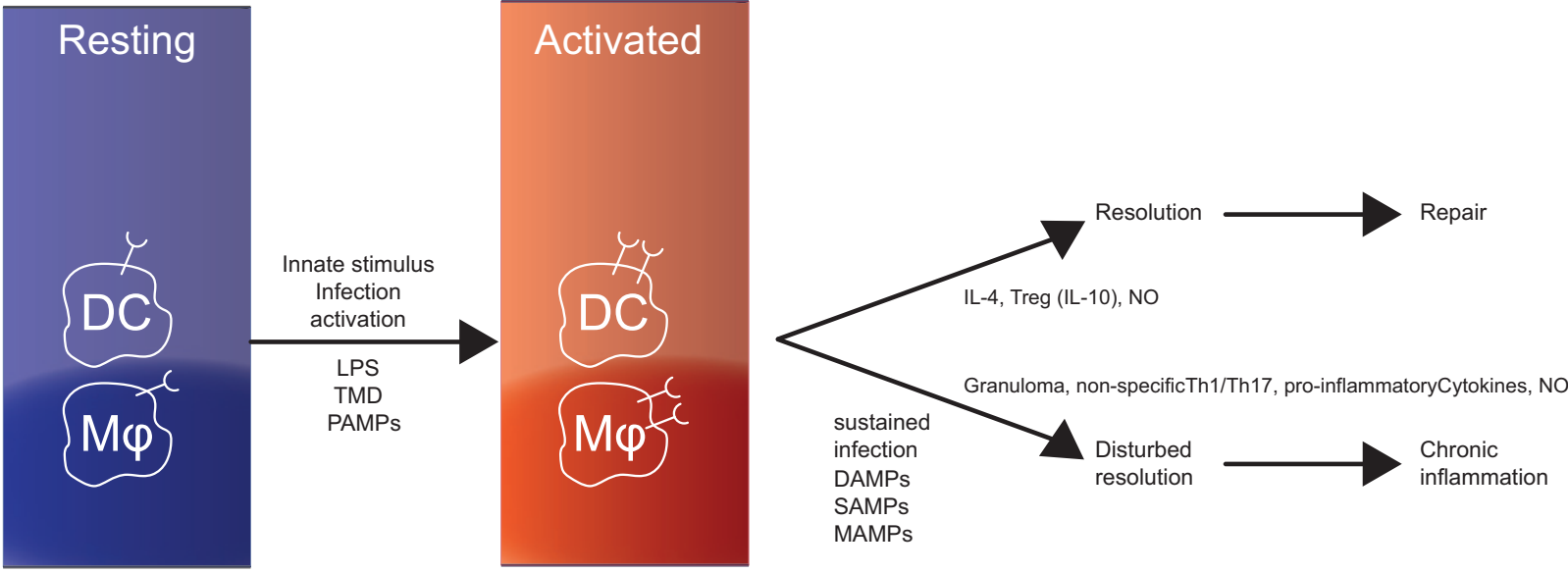

FIGURE 1 | (A) Overview of the ligands of Mincle (top panel) and the signaling pathways described in the current literature. Factors that were also documented in literature related to Crohn's disease are depicted in bold. References of the different ligands not mentioned in the text are for bacterial pathogen species (11-13), Leishmania (14), mycobacteria, and corynebacteria (15, 16), Streptococcus pneumonia (17), Helicobacter pylori (18), Malassezia (19, 20), Aspergillus fumigatus (21), Candida albicans (22, 23), SAP130 (10, 24, 25), $\beta$-glucosylceramide (26), cholesterol crystals (27), and cholesterol sulfate (28). References for the various signaling molecules not mentioned in the text are for TLR4/MyD88 (29), PKC (30), vav proteins (31), HIF1 $\alpha$ (32) and NIrp3 (33, 34). (B) Resting dendritic cells (DCs) and macrophages also do not express Mincle, but they do express macrophage C-type lectin (MCL). Different activating signals induce Mincle expression. Two different pathways induce repair or chronic inflammation as indicated. References for activation and chronic inflammation are given in the text, for the resolution: Th2 skewing via IL-4 (35, 36), IL-10 (37), and NO (38). 
Mincle to excessive and sustained inflammation in CD patients with active disease (86).

Taken together, numerous Mincle-related ligands and signaling molecules can be linked to CD.

\section{HOW COULD MINCLE MEDIATE CD INFLAMMATION?}

The efficacy by which Mincle handles microbes, microbial products, and damaged cells directs whether the outcome will be with suppression or with excess inflammation (see Figure 1B). These pathways can be polarized, but since CD is a chronic relapsing disease the activating signals and wound healing processes might also be present more or less in parallel. Mincle functions as a receptor for different bacteria and fungi, leading to proper immune responses that functions to eradicate pathogens $(38,82)$. Early response mediated via TLRs and MCL expressed on macrophages by a primary infectious stimulus (PAMP) results in the upregulation of Mincle expression. This leads to a sustained signaling process via the activating motif of the FcR $\gamma$ chain and the production of pro-inflammatory cytokines and finally a non-specific activation of Th1/Th17 response. In an appropriate immune response, the end product is the eradication of the infectious agent and resolution of the inflammation. Mincle stimulation can help by inducing antiinflammatory genes and genes involved in wound healing. In case of a sustained infection when pathogenic ligands are still present or because of tissue damage resulting in the presence of DAMPs or self-associated molecular patterns (SAMPs) continuous Mincle signaling remains. TLR- and Mincle co-dependent genes are enriched among genes required to handle persisting D/M/SAMP signals (38).

There are several pathways that counter-regulate Mincle on macrophages and DCs. Among them is the observed effect of IL-4 on Mincle expression of monocyte-derived DCs (87). This is, however, an artificial system, because these cells co-express surface markers (CD83 and DC-SIGN) that are not found to on the same cells in the in vivo situation (88).

In $\mathrm{CD}$, there is evidence that a dysregulated macrophage function and a consecutive defective acute inflammatory response result in the impaired clearance of commensal bacteria. The persistence of the bacteria leads to a chronic granulomatous inflammation. Pathogenic infections may act as triggers or

\section{REFERENCES}

1. Kapsenberg ML. Dendritic-cell control of pathogen-driven T-cell polarization. Nat Rev Immunol (2003) 3(12):984-93. doi:10.1038/nri1246

2. Maloy KJ, Powrie F. Intestinal homeostasis and its breakdown in inflammatory bowel disease. Nature (2011) 474(7351):298-306. doi:10.1038/nature10208

3. Kmiec Z, Cyman M, Slebioda TJ. Cells of the innate and adaptive immunity and their interactions in inflammatory bowel disease. Adv Med Sci (2017) 62(1):1-16. doi:10.1016/j.advms.2016.09.001

4. Ishikawa E, Ishikawa T, Morita YS, Toyonaga K, Yamada H, Takeuchi O, et al. Direct recognition of the mycobacterial glycolipid, trehalose dimycolate, by C-type lectin Mincle. J Exp Med (2009) 206(13):2879-88. doi:10.1084/ jem. 20091750 contributing factors for the chronic inflammation $(2,89)$ that is mediated by other stimuli of various nature, involving microbialassociated molecular patterns, DAMPs, or SAMPs, all described to be ligands of Mincle.

It will be of potential interest to study the direct role of Mincle as a predominant activating C-type lectin receptor via a Syk/Card9-dependent signaling mechanism in CD. Genetic susceptibility, barrier defects, or bacterial handling, dysbiosis or infection, sustained innate immunity, and defective regulation are all layers of a multi-hit model of intestinal inflammation (2). They are combined with different homeostatic modules such as autophagy, ER stress, antimicrobial proteins, the microbiota, PRRs, cytokine modules, and regulatory T cells. Defective modules may predispose people to the development of chronic intestinal inflammation. Determination of the role of Mincle in these layers and modules will reveal if Mincle is an important receptor of mediator of the chronic nature of $\mathrm{CD}$, which could be relevant for therapeutic intervention. Targeting Syk has been suggested as a treatment for allergic and autoimmune disorders (90). In rheumatoid arthritis, inhibition of Syk has been studied as a treatment option (91). Although there is no direct evidence on the role of Mincle in $\mathrm{CD}$, the data on the expression and role of Mincle in health and disease reveal numerous potential starting points. The synergy and antagonisms of the various PRRs, whether these are C-type lectins or TLRs, and their differential regulation on cells of the innate immune system, macrophages, and DCs is an important topic to understand the endogenous adjuvant reaction that they might induce. There are probably multiple mechanisms and interactions that result in the observed pathogenic immune reaction that is the fundament of CD. Here, the surprising overlap between features of $\mathrm{CD}$ and the roles that Mincle plays in a (chronic) immune reaction might indicate that $\mathrm{CD}$ could be an adjuvant reaction induced by Mincle triggering.

\section{AUTHOR CONTRIBUTIONS}

The author confirms being the sole contributor of this work and approved it for publication.

\section{ACKNOWLEDGMENTS}

Dr. R. Snackers from Com-unicate is greatly acknowledged for drawing the figures.
5. Schoenen H, Bodendorfer B, Hitchens K, Manzanero S, Werninghaus K, Nimmerjahn F, et al. Cutting edge: Mincle is essential for recognition and adjuvanticity of the mycobacterial cord factor and its synthetic analog trehalose-dibehenate. J Immunol (2010) 184(6):2756-60. doi:10.4049/ jimmunol.0904013

6. Decout A, Silva-Gomes S, Drocourt D, Barbe S, Andre I, Cueto FJ, et al. Rational design of adjuvants targeting the C-type lectin Mincle. Proc Natl Acad Sci U S A (2017) 114(10):2675-80. doi:10.1073/pnas.1612421114

7. Matsumoto M, Tanaka T, Kaisho T, Sanjo H, Copeland NG, Gilbert DJ, et al. A novel LPS-inducible C-type lectin is a transcriptional target of NF-IL6 in macrophages. J Immunol (1999) 163(9):5039-48.

8. Balch SG, Greaves DR, Gordon S, McKnight AJ. Organization of the mouse macrophage C-type lectin $(\mathrm{Mcl})$ gene and identification of a 
subgroup of related lectin molecules. Eur J Immunogenet (2002) 29(1):61-4. doi:10.1046/j.1365-2370.2002.00266.x

9. Flornes LM, Bryceson YT, Spurkland A, Lorentzen JC, Dissen E, Fossum S. Identification of lectin-like receptors expressed by antigen presenting cells and neutrophils and their mapping to a novel gene complex. Immunogenetics (2004) 56(7):506-17. doi:10.1007/s00251-004-0714-x

10. Yamasaki S, Ishikawa E, Sakuma M, Hara H, Ogata K, Saito T. Mincle is an ITAM-coupled activating receptor that senses damaged cells. Nat Immunol (2008) 9(10):1179-88. doi:10.1038/ni.1651

11. Chinthamani S, Settem RP, Honma K, Kay JG, Sharma A. Macrophage inducible C-type lectin (Mincle) recognizes glycosylated surface (S)-layer of the periodontal pathogen Tannerella forsythia. PLoS One (2017) 12(3):e0173394. doi:10.1371/journal.pone.0173394

12. Kottom TJ, Hebrink DM, Jenson PE, Nandakumar V, Wuthrich M, Wang H, et al. The interaction of pneumocystis with the C-type lectin receptor Mincle exerts a significant role in host defense against infection. J Immunol (2017) 198(9):3515-25. doi:10.4049/jimmunol.1600744

13. Ostrop J, Lang R. Contact, collaboration, and conflict: signal integration of Syk-coupled C-type lectin receptors. J Immunol (2017) 198(4):1403-14. doi:10.4049/jimmunol.1601665

14. Iborra S, Martinez-Lopez M, Cueto FJ, Conde-Garrosa R, Del Fresno C, Izquierdo HM, et al. Leishmania uses Mincle to target an inhibitory ITAM signaling pathway in dendritic cells that dampens adaptive immunity to infection. Immunity (2016) 45(4):788-801. doi:10.1016/j.immuni.2016.09.012

15. van der Peet PL, Nagata M, Shah S, White JM, Yamasaki S, Williams SJ. Lipid structure influences the ability of glucose monocorynomycolate to signal through Mincle. Org Biomol Chem (2016) 14(39):9267-77. doi:10.1039/ C6OB01781A

16. Tima HG, Al Dulayymi JR, Denis O, Lehebel P, Baols KS, Mohammed MO, et al. Inflammatory properties and adjuvant potential of synthetic glycolipids homologous to mycolate esters of the cell wall of Mycobacterium tuberculosis. J Innate Immun (2017) 9(2):162-80. doi:10.1159/000450955

17. Behler-Janbeck F, Takano T, Maus R, Stolper J, Jonigk D, Tort Tarres M, et al. C-type lectin Mincle recognizes glucosyl-diacylglycerol of Streptococcus pneumoniae and plays a protective role in pneumococcal pneumonia. PLoS Pathog (2016) 12(12):e1006038. doi:10.1371/journal.ppat.1006038

18. Devi S, Rajakumara E, Ahmed N. Induction of Mincle by Helicobacter pylori and consequent anti-inflammatory signaling denote a bacterial survival strategy. Sci Rep (2015) 5:15049. doi:10.1038/srep15049

19. Yamasaki S, Matsumoto M, Takeuchi O, Matsuzawa T, Ishikawa E, Sakuma M, et al. C-type lectin Mincle is an activating receptor for pathogenic fungus, Malassezia. Proc Natl Acad Sci U S A (2009) 106(6):1897-902. doi:10.1073/pnas.0805177106

20. Ribbing C, Engblom C, Lappalainen J, Lindstedt K, Kovanen PT, Karlsson MA, et al. Mast cells generated from patients with atopic eczema have enhanced levels of granule mediators and an impaired Dectin-1 expression. Allergy (2011) 66(1):110-9. doi:10.1111/j.1398-9995.2010.02437.x

21. Zhao G, Xu Q, Lin J, Chen W, Cui T, Hu L, et al. The role of Mincle in innate immune to fungal keratitis. J Infect Dev Ctries (2017) 11(1):89-97. doi:10.3855/ jidc. 7570

22. Wells CA, Salvage-Jones JA, Li X, Hitchens K, Butcher S, Murray RZ, et al. The macrophage-inducible C-type lectin, Mincle, is an essential component of the innate immune response to Candida albicans. JImmunol (2008) 180(11):7404-13. doi:10.4049/jimmunol.180.11.7404

23. Bugarcic A, Hitchens K, Beckhouse AG, Wells CA, Ashman RB, Blanchard H. Human and mouse macrophage-inducible C-type lectin (Mincle) bind Candida albicans. Glycobiology (2008) 18(9):679-85. doi:10.1093/glycob/ cwn046

24. Gross O, Gewies A, Finger K, Schafer M, Sparwasser T, Peschel C, et al. Card9 controls a non-TLR signalling pathway for innate anti-fungal immunity. Nature (2006) 442(7103):651-6. doi:10.1038/nature04926

25. Hara H, Ishihara C, Takeuchi A, Imanishi T, Xue L, Morris SW, et al. The adaptor protein CARD9 is essential for the activation of myeloid cells through ITAM-associated and toll-like receptors. Nat Immunol (2007) 8(6):619-29. doi:10.1038/ni1466

26. Nagata M, Izumi Y, Ishikawa E, Kiyotake R, Doi R, Iwai S, et al. Intracellular metabolite beta-glucosylceramide is an endogenous Mincle ligand possessing immunostimulatory activity. Proc Natl Acad Sci U S A (2017) 114(16): E3285-94. doi:10.1073/pnas.1618133114
27. Kiyotake R, Oh-Hora M, Ishikawa E, Miyamoto T, Ishibashi T, Yamasaki S. Human Mincle binds to cholesterol crystals and triggers innate immune responses. J Biol Chem (2015) 290(42):25322-32. doi:10.1074/jbc. M115.645234

28. Kostarnoy AV, Gancheva PG, Lepenies B, Tukhvatulin AI, Dzharullaeva AS, Polyakov NB, et al. Receptor Mincle promotes skin allergies and is capable of recognizing cholesterol sulfate. Proc Natl Acad Sci U S A (2017) 114(13):E2758-65. doi:10.1073/pnas.1611665114

29. Brown GD. Sensing necrosis with Mincle. Nat Immunol (2008) 9(10): 1099-100. doi:10.1038/ni1008-1099

30. Strasser D, Neumann K, Bergmann H, Marakalala MJ, Guler R, Rojowska A, et al. Syk kinase-coupled C-type lectin receptors engage protein kinase $\mathrm{C}$-sigma to elicit Card9 adaptor-mediated innate immunity. Immunity (2012) 36(1):32-42. doi:10.1016/j.immuni.2011.11.015

31. Roth S, Bergmann H, Jaeger M, Yeroslaviz A, Neumann K, Koenig PA, et al. Vav proteins are key regulators of Card9 signaling for innate antifungal immunity. Cell Rep (2016) 17(10):2572-83. doi:10.1016/j.celrep.2016.11.018

32. Schoenen H, Huber A, Sonda N, Zimmermann S, Jantsch J, Lepenies B, et al. Differential control of Mincle-dependent cord factor recognition and macrophage responses by the transcription factors C/EBPbeta and HIFlalpha. J Immunol (2014) 193(7):3664-75. doi:10.4049/jimmunol.1301593

33. Schweneker K, Gorka O, Schweneker M, Poeck H, Tschopp J, Peschel C, et al. The mycobacterial cord factor adjuvant analogue trehalose-6,6'dibehenate (TDB) activates the Nlrp3 inflammasome. Immunobiology (2013) 218(4):664-73. doi:10.1016/j.imbio.2012.07.029

34. Desel C, Werninghaus K, Ritter M, Jozefowski K, Wenzel J, Russkamp N, et al. The Mincle-activating adjuvant TDB induces MyD88-dependent Th1 and Th17 responses through IL-1R signaling. PLoS One (2013) 8(1):e53531. doi:10.1371/journal.pone.0053531

35. Sousa AO, Lee FK, Freiji R, Lagrange PH, Nahmias A. Human immunodeficiency virus infection alters antigen-induced cytokine responses in patients with active mycobacterial diseases. J Infect Dis (1998) 177(6):1554-62. doi:10.1086/515326.

36. Wevers BA, Kaptein TM, Zijlstra-Willems EM, Theelen B, Boekhout T, Geijtenbeek TB, et al. Fungal engagement of the C-type lectin Mincle suppresses dectin-1-induced antifungal immunity. Cell Host Microbe (2014) 15(4):494-505. doi:10.1016/j.chom.2014.03.008

37. Patin EC, Willcocks S, Orr S, Ward TH, Lang R, Schaible UE. Mincle-mediated anti-inflammatory IL-10 response counter-regulates IL-12 in vitro. Innate Immun (2016) 22(3):181-5. doi:10.1177/1753425916636671

38. Lee WB, Kang JS, Choi WY, Zhang Q, Kim CH, Choi UY, et al. Minclemediated translational regulation is required for strong nitric oxide production and inflammation resolution. Nat Commun (2016) 7:11322. doi:10.1038/ ncomms 11322

39. Hunter RL, Hwang SA, Jagannath C, Actor JK. Cord factor as an invisibility cloak? A hypothesis for asymptomatic TB persistence. Tuberculosis (Edinb) (2016) 101S:S2-8. doi:10.1016/j.tube.2016.09.023

40. Patin EC, Geffken AC, Willcocks S, Leschczyk C, Haas A, Nimmerjahn F, et al. Trehalose dimycolate interferes with FcgammaR-mediated phagosome maturation through Mincle, SHP-1 and FcgammaRIIB signalling. PLoS One (2017) 12(4):e0174973. doi:10.1371/journal.pone.0174973

41. Rambaruth ND, Jegouzo SA, Marlor H, Taylor ME, Drickamer K. Mouse Mincle: characterization as a model for human Mincle and evolutionary implications. Molecules (2015) 20(4):6670-82. doi:10.3390/molecules20046670

42. Ostrop J, Jozefowski K, Zimmermann S, Hofmann K, Strasser E, Lepenies B, et al. Contribution of MINCLE-SYK signaling to activation of primary human APCs by mycobacterial cord factor and the novel adjuvant TDB. J Immunol (2015) 195(5):2417-28. doi:10.4049/jimmunol.1500102

43. Byrareddy SN, Little D, Mayne AE, Villinger F, Ansari AA. Phenotypic and functional characterization of monoclonal antibodies with specificity for rhesus macaque CD200, CD200R and Mincle. PLoS One (2015) 10(10):e140689. doi:10.1371/journal.pone.0140689

44. Miyake Y, Toyonaga K, Mori D, Kakuta S, Hoshino Y, Oyamada A, et al. C-type lectin MCL is an FcRgamma-coupled receptor that mediates the adjuvanticity of mycobacterial cord factor. Immunity (2013) 38(5):1050-62. doi:10.1016/j. immuni.2013.03.010

45. Zhao XQ, Zhu LL, Chang Q, Jiang C, You Y, Luo T, et al. C-type lectin receptor dectin-3 mediates trehalose 6,6'-dimycolate (TDM)-induced Mincle expression through CARD9/Bcl10/MALT1-dependent nuclear factor 
(NF)-kappaB activation. J Biol Chem (2014) 289(43):30052-62. doi:10.1074/ jbc.M114.588574

46. Kerscher B, Wilson GJ, Reid DM, Mori D, Taylor JA, Besra GS, et al. Mycobacterial receptor, Clec4d (CLECSF8, MCL), is coregulated with Mincle and upregulated on mouse myeloid cells following microbial challenge. Eur J Immunol (2016) 46(2):381-9. doi:10.1002/eji.201545858

47. Miyake Y, Masatsugu OH, Yamasaki S. C-type lectin receptor MCL facilitates Mincle expression and signaling through complex formation. JImmunol (2015) 194(11):5366-74. doi:10.4049/jimmunol.1402429

48. Kerscher B, Dambuza IM, Christofi M, Reid DM, Yamasaki S, Willment JA, et al. Signalling through MyD88 drives surface expression of the mycobacterial receptors MCL (Clecsf8, Clec4d) and Mincle (Clec4e) following microbial stimulation. Microbes Infect (2016) 18(7-8):505-9. doi:10.1016/j. micinf.2016.03.007

49. Wu XY, Guo JP, Yin FR, Lu XL, Li R, He J, et al. Macrophage-inducible C-type lectin is associated with anti-cyclic citrullinated peptide antibodies-positive rheumatoid arthritis in men. Chin Med J (Engl) (2012) 125(17):3115-9.

50. Nakamura N, Shimaoka Y, Tougan T, Onda H, Okuzaki D, Zhao H, et al. Isolation and expression profiling of genes upregulated in bone marrowderived mononuclear cells of rheumatoid arthritis patients. DNA Res (2006) 13(4):169-83. doi:10.1093/dnares/dsl006

51. Suzuki Y, Nakano Y, Mishiro K, Takagi T, Tsuruma K, Nakamura M, et al. Involvement of Mincle and Syk in the changes to innate immunity after ischemic stroke. Sci Rep (2013) 3:3177. doi:10.1038/srep03177

52. Arumugam TV, Manzanero S, Furtado M, Biggins PJ, Hsieh YH, Gelderblom M, et al. An atypical role for the myeloid receptor Mincle in central nervous system injury. J Cereb Blood Flow Metab (2017) 37(6):2098-111. doi:10.1177/0271678X16661201

53. Saravanan C, Cao Z, Head SR, Panjwani N. Analysis of differential expression of glycosyltransferases in healing corneas by glycogene microarrays. Glycobiology (2010) 20(1):13-23. doi:10.1093/glycob/cwp133

54. Jia R, Hashizume-Takizawa T, Du Y, Yamamoto M, Kurita-Ochiai T. Aggregatibacter actinomycetemcomitans induces Th17 cells in atherosclerotic lesions. Pathog Dis (2015) 73(3):ftu027. doi:10.1093/femspd/ftu027

55. Sharma A, Steichen AL, Jondle CN, Mishra BB, Sharma J. Protective role of Mincle in bacterial pneumonia by regulation of neutrophil mediated phagocytosis and extracellular trap formation. J Infect Dis (2014) 209(11):1837-46. doi:10.1093/infdis/jit820

56. Sharma A, Simonson TJ, Jondle CN, Mishra BB, Sharma J. Mincle-mediated neutrophil extracellular trap formation by regulation of autophagy. J Infect Dis (2017) 215(7):1040-8. doi:10.1093/infdis/jix072

57. Greco SH, Torres-Hernandez A, Kalabin A, Whiteman C, Rokosh R, Ravirala S, et al. Mincle signaling promotes con A hepatitis. J Immunol (2016) 197(7):2816-27. doi:10.4049/jimmunol.1600598

58. Zhou H, Yu M, Zhao J, Martin BN, Roychowdhury S, McMullen MR, et al. IRAKM-Mincle axis links cell death to inflammation: pathophysiological implications for chronic alcoholic liver disease. Hepatology (2016) 64(6):1978-93. doi:10.1002/hep.28811

59. Brown GD, Crocker PR. Lectin receptors expressed on myeloid cells. Microbiol Spectr (2016) 4(5):MCHD-0036. doi:10.1128/microbiolspec. MCHD-0036-2016

60. Mayer S, Raulf MK, Lepenies B. C-type lectins: their network and roles in pathogen recognition and immunity. Histochem Cell Biol (2017) 147(2): 223-37. doi:10.1007/s00418-016-1523-7

61. Naser SA, Ghobrial G, Romero C, Valentine JF. Culture of Mycobacterium avium subspecies paratuberculosis from the blood of patients with Crohn's disease. Lancet (2004) 364(9439):1039-44. doi:10.1016/S0140-6736(04) 17058-X

62. Alcedo KP, Thanigachalam S, Naser SA. RHB-104 triple antibiotics combination in culture is bactericidal and should be effective for treatment of Crohn's disease associated with Mycobacterium paratuberculosis. Gut Pathog (2016) 8:32. doi:10.1186/s13099-016-0115-3

63. Borody TJ, Leis S, Warren EF, Surace R. Treatment of severe Crohn's disease using antimycobacterial triple therapy - approaching a cure? Dig Liver Dis (2002) 34(1):29-38. doi:10.1016/S1590-8658(02)80056-1

64. Ebringer A, Rashid T, Tiwana H, Wilson C. A possible link between Crohn's disease and ankylosing spondylitis via Klebsiella infections. Clin Rheumatol (2007) 26(3):289-97. doi:10.1007/s10067-006-0391-2
65. Liu Y, van Kruiningen HJ, West AB, Cartun RW, Cortot A, Colombel JF. Immunocytochemical evidence of Listeria, Escherichia coli, and Streptococcus antigens in Crohn's disease. Gastroenterology (1995) 108(5):1396-404. doi:10.1016/0016-5085(95)90687-8

66. Miranda-Bautista J, Padilla-Suarez C, Bouza E, Munoz P, Menchen L, MarinJimenez I. Listeria monocytogenes infection in inflammatory bowel disease patients: case series and review of the literature. Eur $J$ Gastroenterol Hepatol (2014) 26(11):1247-52. doi:10.1097/MEG.0000000000000188

67. Rashid T, Ebringer A, Wilson C. The role of Klebsiella in Crohn's disease with a potential for the use of antimicrobial measures. Int J Rheumatol (2013) 2013:610393. doi:10.1155/2013/610393

68. Mazzarella G, Perna A, Marano A, Lucariello A, Aufiero VR, Melina R, et al. Pathogenic role of associated adherent-invasive Escherichia coli in Crohn's disease. J Cell Physiol (2017) 232(10):2860-8. doi:10.1002/jcp.25717

69. Shea KM, Edelsberg J, Weycker D, Farkouh RA, Strutton DR, Pelton SI. Rates of pneumococcal disease in adults with chronic medical conditions. Open Forum Infect Dis (2014) 1(1):ofu024. doi:10.1093/ofid/ofu024

70. Long MD, Farraye FA, Okafor PN, Martin C, Sandler RS, Kappelman MD. Increased risk of pneumocystis jiroveci pneumonia among patients with inflammatory bowel disease. Inflamm Bowel Dis (2013) 19(5):1018-24. doi:10.1097/MIB.0b013e3182802a9b

71. Mimouna S, Bazin M, Mograbi B, Darfeuille-Michaud A, Brest P, Hofman P, et al. HIF1A regulates xenophagic degradation of adherent and invasive Escherichia coli (AIEC). Autophagy (2014) 10(12):2333-45. doi:10.4161/15548627.2014.984275

72. Dhillon SS, Mastropaolo LA, Murchie R, Griffiths C, Thoni C, Elkadri A, et al. Higher activity of the inducible nitric oxide synthase contributes to very early onset inflammatory bowel disease. Clin Transl Gastroenterol (2014) 5:e46. doi:10.1038/ctg.2013.17

73. Soufli I, Toumi R, Rafa H, Touil-Boukoffa C. Overview of cytokines and nitric oxide involvement in immuno-pathogenesis of inflammatory bowel diseases. World J Gastrointest Pharmacol Ther (2016) 7(3):353-60. doi:10.4292/wjgpt. v7.i3.353

74. Wolfkamp SC, Te Velde AA, Weersma RK, Ponsioen CY, Stokkers PC. Is there a role for Crohn's disease-associated autophagy genes ATG16L1 and IRGM in formation of granulomas? Eur J Gastroenterol Hepatol (2010) 22(8):933-7. doi:10.1097/MEG.0b013e32833775e6

75. Lang R. Recognition of the mycobacterial cord factor by Mincle: relevance for granuloma formation and resistance to tuberculosis. Front Immunol (2013) 4:5. doi:10.3389/fimmu.2013.00005

76. Sato IY, Kobayashi K, Yamagata N, Shikama Y, Kasama T, Kasahara K, et al. Modulation of granuloma formation in vitro by endogenous mediators. Immunopharmacology (1991) 21(2):73-82. doi:10.1016/ 0162-3109(91)90010-V

77. Baram L, Cohen-Kedar S, Spektor L, Elad H, Guzner-Gur H, Dotan I. Differential stimulation of peripheral blood mononuclear cells in Crohn's disease by fungal glycans. J Gastroenterol Hepatol (2014) 29(12):1976-84. doi:10.1111/jgh.12701

78. Jyonouchi H, Geng L, Cushing-Ruby A, Monteiro IM. Aberrant responses to TLR agonists in pediatric IBD patients; the possible association with increased production of Th1/Th17 cytokines in response to Candida, a luminal antigen. Pediatr Allergy Immunol (2010) 21(4 Pt 2):e747-55. doi:10.1111/j.1399-3038.2009.00923.x

79. Xu X, Sun S, Xie F, Ma J, Tang J, He S, et al. Advanced oxidation protein products induce epithelial-mesenchymal transition of intestinal epithelial cells via a PKC delta-mediated, redox-dependent signaling pathway. Antioxid Redox Signal (2017) 27(1):37-56. doi:10.1089/ars.2015.6611

80. Fairfax BP, Humburg P, Makino S, Naranbhai V, Wong D, Lau E, et al. Innate immune activity conditions the effect of regulatory variants upon monocyte gene expression. Science (2014) 343(6175):1246949. doi:10.1126/ science. 1246949

81. Sokol H, Conway KL, Zhang M, Choi M, Morin B, Cao Z, et al. Card9 mediates intestinal epithelial cell restitution, T-helper 17 responses, and control of bacterial infection in mice. Gastroenterology (2013) 145(3):591-601e3. doi:10.1053/j.gastro.2013.05.047

82. Pilmis B, Puel A, Lortholary O, Lanternier F. New clinical phenotypes of fungal infections in special hosts. Clin Microbiol Infect (2016) 22(8):681-7. doi:10.1016/j.cmi.2016.05.016 
83. Nasir A, El Bahesh E, Whitten C, Lawson A, Udall JN Jr. Pityrosporum folliculitis in a Crohn's disease patient receiving infliximab. Inflamm Bowel Dis (2010) 16(1):7-8. doi:10.1002/ibd.20928

84. Marcoval J, Penin RM, Sabe N, Valenti-Medina F, Bonfill-Orti M, MartinezMolina L. Cutaneous leishmaniasis associated with anti-tumour necrosis factor-alpha drugs: an emerging disease. Clin Exp Dermatol (2017) 42(3):331-4. doi:10.1111/ced.13061

85. Castano-Rodriguez N, Kaakoush NO, Lee WS, Mitchell HM. Dual role of Helicobacter and Campylobacter species in IBD: a systematic review and meta-analysis. Gut (2017) 66(2):235-49. doi:10.1136/gutjnl-2015-310545

86. Mueller C. Danger-associated molecular patterns and inflammatory bowel disease: is there a connection? Dig Dis (2012) 30(Suppl 3):40-6. doi:10.1159/000342600

87. Hupfer T, Schick J, Jozefowski K, Voehringer D, Ostrop J, Lang R. Stat6Dependent inhibition of Mincle expression in mouse and human antigenpresenting cells by the Th2 cytokine IL-4. Front Immunol (2016) 7:423. doi:10.3389/fimmu.2016.00423

88. te Velde AA, van Kooyk Y, Braat H, Hommes DW, Dellemijn TA, Slors JF, et al. Increased expression of DC-SIGN+IL-12+IL-18+ and CD83+IL-12-IL-18dendritic cell populations in the colonic mucosa of patients with Crohn's disease. Eur J Immunol (2003) 33(1):143-51. doi:10.1002/immu.200390017
89. Smith AM, Rahman FZ, Hayee B, Graham SJ, Marks DJ, Sewell GW, et al Disordered macrophage cytokine secretion underlies impaired acute inflammation and bacterial clearance in Crohn's disease. J Exp Med (2009) 206(9):1883-97. doi:10.1084/jem.20091233

90. Wong BR, Grossbard EB, Payan DG, Masuda ES. Targeting Syk as a treatment for allergic and autoimmune disorders. Expert Opin Investig Drugs (2004) 13(7):743-62. doi:10.1517/13543784.13.7.743

91. Nijjar JS, Tindell A, McInnes IB, Siebert S. Inhibition of spleen tyrosine kinase in the treatment of rheumatoid arthritis. Rheumatology (Oxford) (2013) 52(9):1556-62. doi:10.1093/rheumatology/ket225

Conflict of Interest Statement: The author declares that the research was conducted in the absence of any commercial or financial relationships that could be construed as a potential conflict of interest.

Copyright (C) 2017 te Velde. This is an open-access article distributed under the terms of the Creative Commons Attribution License (CC BY). The use, distribution or reproduction in other forums is permitted, provided the original author(s) or licensor are credited and that the original publication in this journal is cited, in accordance with accepted academic practice. No use, distribution or reproduction is permitted which does not comply with these terms. 